\title{
Young, healthy males and females present cardiometabolic protection against the detrimental effects of a 7-day high-fat high-calorie diet
}

\author{
Katie L. Whytock ${ }^{1}$ (D) . Sam O. Shepherd ${ }^{1}$ (D) ${\text { Matt } \text { Cocks }^{1} \text { (D) } \cdot \text { Anton J. M. Wagenmakers }}^{1}$ (D) Juliette A. Strauss ${ }^{1}$ (D)
}

Received: 30 March 2020 / Accepted: 3 August 2020 / Published online: 13 August 2020

(c) The Author(s) 2020

\begin{abstract}
Purpose High-fat, high-calorie (HFHC) diets have been used as a model to investigate lipid-induced insulin resistance. Short-term HFHC diets reduce insulin sensitivity in young healthy males, but to date, no study has directly compared males and females to elucidate sex-specific differences in the effects of a HFHC diet on functional metabolic and cardiovascular outcomes.

Methods Eleven males ( $24 \pm 4$ years; BMI $23 \pm 2 \mathrm{~kg} \cdot \mathrm{m}^{-2} ; \mathrm{VO}_{2}$ peak $\left.62.3 \pm 8.7 \mathrm{ml} \cdot \mathrm{min}^{-1} \cdot \mathrm{kg}^{-1} \mathrm{FFM}\right)$ were matched to 10 females $\left(25 \pm 4\right.$ years; BMI $\left.23 \pm 2 \mathrm{~kg} \cdot \mathrm{m}^{-2} ; \mathrm{VO}_{2 \text { peak }} 58.2 \pm 8.2 \mathrm{ml} \cdot \mathrm{min}^{-1} \cdot \mathrm{kg}^{-1} \mathrm{FFM}\right)$. Insulin sensitivity, measured via oral glucose tolerance test, metabolic flexibility, arterial stiffness, body composition and blood lipids and liver enzymes were measured before and after 7 days of a high-fat (65\% energy) high-calorie $(+50 \% \mathrm{kcal})$ diet.

Results The HFHC diet did not change measures of insulin sensitivity, metabolic flexibility or arterial stiffness in either sex. There was a trend towards increased total body fat mass $(\mathrm{kg})$ after the HFHC diet $(+1.8 \%$ and $+2.3 \%$ for males and females, respectively; $P=0.056)$. In contrast to females, males had a significant increase in trunk to leg fat mass ratio $(+5.1 \%$; $P=0.005)$.

Conclusion Lean, healthy young males and females appear to be protected from the negative cardio-metabolic effects of a 7-day HFHC diet. Future research should use a prolonged positive energy balance achieved via increased energy intake and reduced energy expenditure to exacerbate negative metabolic and cardiovascular functional outcomes to determine whether sex-specific differences exist under more metabolically challenging conditions.
\end{abstract}

Keywords High-fat $\cdot$ High-calorie $\cdot$ Metabolic health $\cdot$ Sex differences

\section{Introduction}

A western lifestyle is characterised by regular consumption of readily available energy-dense foods [1], often paired with sedentary behaviour throughout the day [2] and/or minimal amounts of exercise [3]. These behavioural patterns are associated with an increased risk of obesity, type 2 diabetes (T2D) and cardiovascular disease [4-6]. At present, cardiovascular disease is established as the leading cause of mortality in western countries [7] and T2D vastly increases the risk of cardiovascular complications [8].

Insulin resistance is defined as impaired insulin-stimulated glucose uptake in skeletal muscle and adipose tissue

Juliette A. Strauss

j.a.strauss@1jmu.ac.uk

1 Research Institute of Sport and Exercise Science, Liverpool John Moores University, Liverpool, UK stores often combined with impaired insulin-induced suppression of hepatic glucose production. Both hepatic and skeletal muscle insulin resistance are central to the development of T2D [9] [10]. Metabolic flexibility is closely linked with skeletal muscle insulin sensitivity [11], and is defined as the capacity to switch from high rates of lipid oxidation in the fasted state to an increased rate of carbohydrate oxidation under insulin-stimulated conditions [12]. Metabolic flexibility is often diminished in obese insulin-resistant individuals in comparison to the lean insulin-sensitive state [13].

Whilst obesity itself is commonly associated with insulin resistance and T2D [14], it is now clear that distinct fat patterning is more closely related with disease risk [15]. For example, fat accumulation in the abdominal region, and in particular visceral fat, is strongly related to metabolic disease and systemic inflammation [16-19], whilst peripheral adipose tissue located in the gluteal-femoral regions appears to be protective against metabolic disease [20]. Abdominal 
adiposity is a typical feature of the male population, with females tending to accumulate fat in the gluteal-femoral region [21]. These differences in adipose tissue storage between sexes likely underpin the sex differences in the risk for developing metabolic disease. Epidemiological studies have shown that the incidence of T2D and cardiovascular disease is lower in females compared to males [7, 22, 23]. Large cross-sectional studies have also shown that males (35-65 years) have a higher prevalence $(+1.3-1.9 \%)$ of elevated fasting glucose in comparison to females [24, 25]. In another cross-sectional study, males (18-32 years) had a reduced blood glucose clearance capacity $(-15 \%)$ following an intravenous glucose tolerance test compared to females [26]. Smaller clinical trials investigating insulin sensitivity in BMI and age-matched males and pre-menopausal females (20-45 years) using a hyperinsulinaemic euglycaemic (HE) clamp have established that females exhibit a similar or higher glucose infusion rate per kilogram of body weight (+36-47\%) when compared to males [27-31], and a markedly higher glucose infusion rate when adjusted per kilogram of lean mass (45-98\%) [28, 31].

Despite females being at a reduced risk of developing insulin resistance and cardio-metabolic disease, there is little research investigating the differences in the progression of insulin resistance and negative cardio-metabolic health between the sexes. One approach to investigate this is to provide excess lipid through an acute lipid infusion during a HE clamp, and it has been shown that a $7 \mathrm{~h}$ lipid infusion caused less of a reduction in glucose infusion in females (26\%) in comparison to males (38\%) [32].

Excess lipid exposure from infusion studies may only illustrate acute physiological responses, whereas more prolonged consumption of a high-fat high-calorie (HFHC) diet provides a chronic stimulus to investigate the influence of increased fat and energy intake (creating a positive energy balance) on adipose tissue stores and early abnormalities in metabolic and cardiovascular regulation. In healthy individuals, consumption of a HFHC diet for 5-7 days has been demonstrated to reduce hepatic insulin sensitivity $(-65 \%)$ [33] and peripheral insulin sensitivity (-20\%) [34] during a HE clamp. HFHC diets also reduced whole-body insulin sensitivity $(-27 \%)$ measured with an oral glucose tolerance test [35] or glucose tolerance $(-11 \%)$ measured after ingestion of a mixed meal (112 g carbohydrate in a $771 \mathrm{kcal}$ meal) [36]. Although some of these studies have included female participants $[35,36]$, to date, no study has directly compared sexes to identify the sex-specific cardiovascular and metabolic responses to a short-term HFHC diet. This is a considerable oversight considering females, compared to males, exhibit higher insulin sensitivity and tend to store fat peripherally, rather than centrally, and therefore appear to be better protected against metabolic disease. Establishing whether females are better equipped to handle lipid overload from a 7-day HFHC diet will be beneficial in underpinning the pathology of T2D in this understudied cohort. Consequently, the aim of this study was to investigate the hypothesis that females matched for age, BMI, cardio-respiratory fitness and habitual activity levels are better protected than males in developing insulin resistance induced by a HFHC diet. We also aim to underpin sex-specific differences in metabolic and cardiovascular functional outcomes (fat mass accumulation, metabolic flexibility, arterial stiffness and blood lipid and liver concentrations) in response to the 7-day HFHC diet.

\section{Methods}

\section{Subjects and ethical approval}

A cohort of young healthy males $(n=11)$ and females $(n=11)$ were matched for BMI $\left(\mathrm{kg} . \mathrm{m}^{-2}\right)$, age and $\mathrm{VO}_{2 \text { peak }}$ $\left[\mathrm{ml} . \mathrm{min}^{-1} \cdot \mathrm{kg} \text { (fat-free mass (FFM) }\right)^{-1}$ ] (see Table 1 for characteristics). $\mathrm{VO}_{2 \text { peak }}$ was adjusted to FFM to remove the influence of increased fat mass on body mass observed in the female cohort allowing for direct comparison of sexes. The sample size for this experiment was estimated based on previous literature that showed a reduction in glucose tolerance or insulin sensitivity following 7 days of a highfat $(65 \%$ energy) high-calorie diet $(+50 \% \mathrm{kcal})[35,36]$. Written informed consent was obtained from all participants. The study protocol adhered to the Declaration of Helsinki and was approved by NHS West Midlands, Black Country Research Ethics Committee. All participants were free from cardiovascular or metabolic disorders, physically active (exercising at least 3 times per week for more than $30 \mathrm{~min}$ at a time) and non-smokers. Additionally, females were required to have a regular menstrual cycle, not be pregnant or breast-feeding during the study and only using the following contraceptive methods; condoms, diaphragm,

Table 1 Participants characteristics

\begin{tabular}{lll}
\hline & Males & Females \\
\hline$n$ & 11 & 10 \\
Age (years) & $24 \pm 4$ & $25 \pm 4$ \\
Body mass $(\mathrm{kg})^{*}$ & $72.6 \pm 5.3$ & $63.9 \pm 9.5$ \\
$\mathrm{BMI}\left(\mathrm{kg} \cdot \mathrm{m}^{-2}\right)$ & $23 \pm 2$ & $23 \pm 2$ \\
$\mathrm{VO}_{2 \text { peak }}\left(\mathrm{L} \cdot \mathrm{min}^{-1}\right)^{*}$ & $3.60 \pm 0.59$ & $2.51 \pm 0.48$ \\
$\mathrm{VO}_{2 \text { peak }}\left(\mathrm{ml} . \mathrm{min}^{-1} \cdot \mathrm{kgFFM}^{-1}\right)$ & $62.3 \pm 8.7$ & $58.2 \pm 8.2$ \\
Matsuda ISI & $11.6 \pm 10.5$ & $9.2 \pm 3.4$ \\
\hline
\end{tabular}

Data provided as mean $\pm \mathrm{SD}$

$B M I$ body mass index, $F M$ fat mass, $F F M$ fat-free mass, ISI insulin sensitivity index

*Significant difference between sexes $P<0.05$ 
IUD (intrauterine device), combined pill. Due to the nature of the dietary intervention, vegetarians and vegans were excluded from participation. During the dietary intervention, one female participant withdrew from participation due to gastro-intestinal discomfort and, therefore, her data were withdrawn from the analyses. Withdrawal of this participant did not affect the group matching of sexes.

\section{Pre-experimental procedures}

Prior to the start of the study, participants attended the laboratory following an overnight fast $(\geq 10 \mathrm{~h})$ for baseline assessments of body composition, resting energy expenditure (REE) and $\mathrm{VO}_{2 \text { peak }}$ (Fig. 1). Body composition was measured using whole-body fan beam dual-energy X-ray absorptiometry (DEXA) (Hologic QDR Series, Discovery A, Bedford, MA, USA). Following removal of jewellery and metal objects, participants were scanned $(\sim 180 \mathrm{~s})$ in a supine position. Each scan was automatically analysed with the QDR software; however, the operator manually corrected the trunk and limb regions and an area identifying visceral adipose tissue (VAT). Percentage body fat (\%), total body fat $(\mathrm{kg})$ and FFM $(\mathrm{kg})$ are presented as subtotal values excluding head measurements to reduce measurement error.

Following the DEXA scan, participants' REE was measured using a Moxus Modular Metabolic system (AEI Technologies, IL, USA). Participants were required to lay in a supine position in a dark room for $10 \mathrm{~min}$ before the Moxus ventilation hood was placed over their head and shoulders for a further $20 \mathrm{~min}$. Volume flow rate was maintained above $25 \mathrm{~L} \cdot \mathrm{min}^{-1}$. The first $5 \mathrm{~min}$ of data was discarded according to best practice methods [37]. REE was calculated towards the end of the $20 \mathrm{~min}$ period, averaged over a 5 min stable period where coefficient of variation for $\mathrm{VO}_{2}$ and $\mathrm{VCO}_{2}$ was $\leq 10 \%$. REE $(\mathrm{kcal} / \mathrm{min})$ was calculated using the Weir equation where

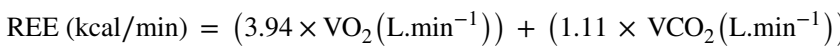
[38]. This number was then used to calculate REE (Kcal/ day) over an entire day.

Participants also performed a progressive exercise test to exhaustion on an electronically-braked cycle ergometer (Lode Corival, Lode B.V, Groningen, Holland) to determine $\mathrm{VO}_{2 \text { peak }}$ using the Moxus Modular Metabolic system (AEI Technologies, IL, USA). The test consisted of cycling initially at $60 \mathrm{~W}$, followed by sequential increments of $35 \mathrm{~W}$ every 3 min until cadence was reduced to $<50 \mathrm{rpm}$, at which point the test was terminated. $\mathrm{VO}_{2 \text { peak }}\left(\mathrm{L} \cdot \mathrm{min}^{-1}\right.$ ) was taken as the highest value obtained in the last $30 \mathrm{~s}$ of the test. This value was then expressed relative to fat-free mass (FFM) $(\mathrm{kg})$ obtained from the DEXA scan to give a $\mathrm{VO}_{2 \text { peak }}\left(\mathrm{ml} \cdot \mathrm{min}^{-1} \cdot \mathrm{kg}(\mathrm{FFM})^{-1}\right)$ normalised for fat-free mass body weight allowing males and females to be compared directly.

Following pre-experimental testing, participants were provided with a 3 -axis activity monitor (wGT3X-BT, ActiGraph, Pensacola, FL, USA) and a food diary to record habitual activity levels and food intake, respectively. Participants were advised to continue habitual activity levels whilst wearing the activity monitor on their right waist for a duration of 3 days ( 2 weekdays and 1 weekend day). Participants were provided with detailed written and verbal instructions on how to complete the 3-day food diary (2 weekdays and 1 weekend day), including information on quantity, food preparation, brand information and cooking methods. Habitual diets were later analysed manually for total daily intake (kcal) and macronutrient breakdown (Table 2).

Table 2 Estimated energy requirements and actual HFHC energy intakes

\begin{tabular}{lcc}
\hline & Males $(n=11)$ & Females $(n=10)$ \\
\hline $\begin{array}{l}\text { Self-reported habitual intake } \\
\quad \text { kcal) }\end{array}$ & $2639 \pm 453$ & $2193 \pm 407$ \\
Self-reported diet fat intake (\%) & $33 \pm 2$ & $34 \pm 7$ \\
Estimated TEE (kcal) & $2653 \pm 407$ & $2259 \pm 349$ \\
Required HFHC intake (kcal) & $3979 \pm 610$ & $3389 \pm 523$ \\
Actual HFHC intake (kcal) & $4063 \pm 669$ & $3464 \pm 357$ \\
HFHC diet fat intake (\%) & $65 \pm 1$ & $65 \pm 1$ \\
HFHC diet saturated fat intake (\% & $37 \pm 3$ & $37 \pm 2$ \\
of overall fat) & & \\
\hline
\end{tabular}

Data provided as mean $\pm \mathrm{SD}$

TEE total energy expenditure
Fig. 1 Schematic diagram of study design. DEXA dualenergy X-ray absorptiometry, $O G T T$ oral glucose tolerance test, $P A$ physical activity, $R E E$ resting energy expenditure

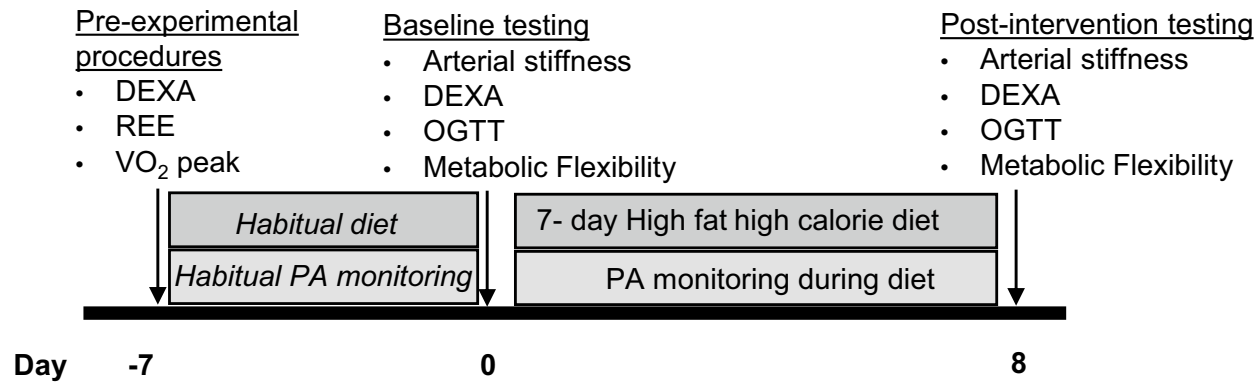




\section{Experimental design}

Participants were advised to consume their habitual diet 7 days prior to pre-testing. Experimental testing was conducted pre- and post-7-day HFHC diet (Fig. 1). Pre-testing for female participants occurred between days 1-6 of the menstrual cycle (follicular phase) to minimise the impact of fluctuations of sex hormones on the results. Participants attended the laboratory following an overnight fast ( $\geq 10 \mathrm{~h}$ ) after abstaining from caffeine, alcohol and vigorous exercise the day before testing. The following measurements were conducted pre- and post-HFHC diet intervention in addition to a DEXA scan, as previously described.

\section{Arterial stiffness}

Participants rested in a supine position for $15 \mathrm{~min}$ before 3 brachial artery blood pressure measurements were conducted using an automated sphygmomanometer (GE CARESCAPE V100-1 Patient monitor, GE Healthcare, Chicago, USA). Arterial stiffness was measured using central (carotid- femoral) pulse wave velocity (aPWV) using a semi-automated device and software (SphygmoCor, AtCor Medical, Sydney, Australia) as previously described [39]. Systemic wave reflection was investigated using pulse wave analysis to produce an augmentation index with the semi-automated device and software (SphymoCor; [39]). The augmentation index was normalised to a heart rate of $75 \mathrm{bpm}\left(\mathrm{AI}_{\mathrm{x}} @ 75 \mathrm{bpm}\right)$ to account for confounding influence of heart rate. All measurements were made in triplicate.

\section{Oral glucose tolerance test}

A $20 \mathrm{G}$ cannula (BD Venflon ${ }^{\mathrm{TM}}$, BD, Oxford, England) was inserted into an antecubital vein to allow for repeated blood sampling during the oral glucose tolerance test (OGTT). A $10 \mathrm{ml}$ blood sample was obtained at baseline before participants consumed a $75 \mathrm{~g}$ glucose drink made with $225 \mathrm{ml}$ of water. Subsequent blood samples $(10 \mathrm{ml})$ were obtained at 15, 30, 45, 60, 90 and 120 min following glucose ingestion. Blood samples were divided equally between vacutainers containing EDTA or a clotting agent (silicon and micronized silica) (BD, Oxford, England) to allow for the separation of plasma and serum, respectively. Prior to centrifugation, EDTA tubes were stored on ice, whereas serum tubes were left at room temperature until clotting had occurred. Blood tubes were centrifuged at $1000 \mathrm{~g}$ for $10 \mathrm{~min}$ at $4{ }^{\circ} \mathrm{C}$ before being stored at $-80^{\circ} \mathrm{C}$ for subsequent analysis.

\section{Metabolic flexibility}

Prior to the OGTT, participants rested in a supine position for $20 \mathrm{~min}$ in a dark room with a ventilation hood placed over their head and shoulders (Moxus Modular Metabolic System, AEI Technologies, IL, USA). $\mathrm{VO}_{2}$ and $\mathrm{VCO}_{2}$ were measured from the collected expired air and used to calculate the respiratory exchange ratio (RER). The first $5 \mathrm{~min}$ of data was discarded according to best practice methods [37]. Fasting RER was averaged over a 5 min stable period where coefficient of variation for $\mathrm{VO}_{2}$ and $\mathrm{VCO}_{2}$ was $\leq 10 \%$. The Moxus ventilation hood was removed for a brief period ( $\leq 2 \mathrm{~min}$ ) to allow participants to consume the glucose beverage before being returned over their head and shoulders for the remainder of the OGTT. The Moxus volume flow rate was maintained at $>25 \mathrm{~L} \cdot \mathrm{min}^{-1}$. For the remaining OGTT, RER was averaged over 5 min intervals. Peak RER following glucose ingestion was identified as the maximum RER obtained at any $5 \mathrm{~min}$ interval during the $120 \mathrm{~min}$ OGTT. The time that peak RER was obtained was recorded and used in the following equation to calculate metabolic flexibility.

Metabolic flexibility $=\frac{\text { Peak RER }- \text { Fasting RER }}{\text { Time to reach peak RER }}$

\section{Blood analyses}

Serum samples were analysed for glucose (all time points during OGTT) and fasting non-esterified fatty acids (NEFA), triglycerides, cholesterol, aspartate aminotransferase (AST), alanine aminotransferase (ALT) and gamma-glutamyltransferase (GGT) concentrations using commercially available spectrophotometric assays (Randox) with a semi-automatic analyser (Randox Daytona RX, Randox, Crumlin, UK). Plasma samples from the OGTT were analysed for insulin concentrations with a commercially available direct insulin ELISA kit (Fisher Scientific, Loughborough, UK).

\section{Calculations}

Glucose area under the curve (AUC) and insulin AUC during the OGTT were calculated using the trapezoidal rule with zero as baseline.

Whole-body insulin sensitivity was calculated using the Matsuda insulin sensitivity index (ISI) [40] with the following equation;

Matsuda ISI $=\frac{10,000}{\sqrt{(\mathrm{FPG} \times \mathrm{FPI}) \times(\mathrm{MPG} \times \mathrm{MPI})}}$

Hepatic and muscle insulin resistance indexes were estimated using the following equations from Abdul-Ghani et al. [41];

Hepatic insulin resistance index $=\mathrm{PG} \mathrm{AUC} \mathrm{AU}_{0 \text { min }} \times \mathrm{PI} \mathrm{AUC}_{0-30 \mathrm{~min}}$

Muscle insulin resistance index $=\mathrm{dG} / \mathrm{dt} \div \mathrm{MPI}$ 
where FGP is fasting plasma glucose, FPI is fasting plasma insulin, MPG is mean plasma glucose during the OGTT, MPI is mean plasma insulin during the OGTT, PG AUC 0-30 min is plasma glucose area under the curve from 0 to $30 \mathrm{~min}$, PI $\mathrm{AUC}_{0-30 \mathrm{~min}}$ is plasma insulin area under the curve from 0 to $30 \mathrm{~min}$ and $\mathrm{dG} / \mathrm{dt}$ is rate of change in plasma glucose from its peak to its nadir.

\section{Seven day HFHC diet}

Although habitual dietary intake was assessed (Table 2), there are known issues with participants under-reporting food intake [42] and therefore the energy value of the HFHC was determined based on REE and physical activity levels. The participants were highly active, as measured objectively by accelerometry and subjectively by the International Physical Activity Questionnaire (IPAQ) [43]. As fitness and activity levels were similar between sexes, the same activity factor of 1.7 was multiplied by REE for both males and females to calculate total energy expenditure (TEE), before being multiplied by 1.5 to calculate each individual's energy intake required during the HFHC diet (Table 2). The diets were designed so that fat contributed $65 \%$ of total energy intake, with approximately $37 \%$ of fat intake derived from saturated fat. The remaining energy was provided from carbohydrate $(\sim 17 \%)$ and protein $(\sim 18 \%)$. All food was purchased and provided by the research team, in addition to a set of scales provided to the participants so all food items could be weighed correctly. Food for the diet was selected such that it would require minimal preparation and cooking by each participant. Where cooking was required, participants were given strict instructions on how to cook the food and were provided with the quantity of cooking oil/butter where necessary.

To increase compliance to the diet, all participants were provided with a HFHC diet plan prior to the intervention to ensure palatability with all foods. Participants were instructed of the importance to consume all food on their HFHC dietary plan and to not consume any other food products. Participants were advised to report and return any food items that they could not consume during the diet so that energy intake and macronutrient percentage could be adjusted as necessary. All participants were required to record the food items and note the time they consumed them in an individual food diary. Each participant was instructed to continue their habitual physical activity (PA) levels and wore the 3-axis activity monitor (wGT3X-BT, ActiGraph, Pensacola, FL, USA) to ensure habitual PA levels remained constant.

\section{Statistics}

An independent $t$ test was used to confirm equal matching of male and female participants for age, BMI and $\mathrm{VO}_{2}$ peak $[\mathrm{ml}$. $\left.\mathrm{min}^{-1} \cdot \mathrm{kg}(\mathrm{FFM})^{-1}\right]$. All metabolic and cardiovascular functional outcomes were analysed using a two-factor repeated measures ANOVA, with the between-subjects-factor 'sex' (males vs. females) and within-subjects-factor 'HFHC diet' (pre- vs. post-diet). Significant main effects and interactions were assessed post hoc using Bonferroni adjustment analysis.

\section{Results}

\section{Subject characteristics}

At baseline, there was no significant difference between males and females for age, BMI and $\mathrm{VO}_{2 \text { peak }}\left(\mathrm{ml} . \mathrm{min}^{-1}\right.$. $\left.\mathrm{kg}(\mathrm{FFM})^{-1}\right)(P>0.05$; Table 1). Of the females who completed the HFHC diet, 4 were using the combined pill contraceptive method.

\section{Energy intake and macronutrient composition during the HFHC diet}

All participants returned their HFHC diet plan with confirmation of times that they had consumed the food throughout the 7 days. All participants adhered to the HFHC diet and any food that was not consumed by the participants was notified to the researchers and returned to the laboratory to allow HFHC diet calculations to be adjusted. Both sexes consumed an equal proportion of dietary fat as saturated fat (Table 2). All participants continued their habitual exercise regime throughout the 7-day HFHC diet period. Average daily physical activity energy expenditure calculated from the 3-axis activity monitor (wGT3X-BT, ActiGraph, Pensacola, FL, USA) revealed no significant differences between habitual physical activity levels $(535 \pm 224 \mathrm{kcal})$ and during the HFHC $(510 \pm 229 \mathrm{kcal})$ for either sex $(P=0.552)$.

\section{Body composition}

Prior to the HFHC diet (baseline), males had significantly higher body mass than females $(P<0.009)$, but there was no effect of the HFHC diet on body mass for either sex $(P=0.121)$. Although matched for BMI, at baseline, females had a significantly higher body fat percentage $(P<0.001)$ and total fat mass $(P=0.003$; Table 3$)$. Conversely at baseline, males had significantly higher FFM $(P<0.001)$, 
Table 3 Effect of 7-days HFHC diet on body composition

\begin{tabular}{lrrrrr}
\hline & \multicolumn{2}{l}{ Males } & & \multicolumn{2}{l}{ Females } \\
\cline { 2 - 3 } \cline { 6 - 6 } & Pre $(n=11)$ & Post $(n=11)$ & & Pre $(n=10)$ & Post $(n=10)$ \\
\hline Body mass $(\mathrm{kg})$ & $72.9 \pm 4.9^{*}$ & $73.2 \pm 5.2$ & & $63.7 \pm 9.3$ & $63.9 \pm 2.9$ \\
BMI $\left(\mathrm{kg} . \mathrm{m}^{-2}\right)$ & $23.2 \pm 1.4$ & $23.3 \pm 1.4$ & & $23.2 \pm 1.5$ & $22.8 \pm 2.4$ \\
FM $(\mathrm{kg})$ & $11.7 \pm 3.1^{*}$ & $11.9 \pm 3.0$ & & $17.3 \pm 4.1$ & $17.7 \pm 4.0$ \\
FFM $(\mathrm{kg})$ & $58.6 \pm 5.5^{*}$ & $57.9 \pm 1.2$ & & $43.2 \pm 5.9$ & $40.3 \pm 10.0$ \\
Body fat $(\%)$ & $16.8 \pm 4.0^{*}$ & $16.9 \pm 3.8$ & & $28.4 \pm 3.6$ & $29 \pm 3.3$ \\
Trunk fat mass $(\mathrm{kg})$ & $5.4 \pm 1.4$ & $5.6 \pm 1.4$ & & $6.7 \pm 2.0$ & $6.6 \pm 2.0$ \\
Trunk/leg fat ratio & $0.87 \pm 0.13^{*}$ & $0.92 \pm 0.17^{*}$ & & $0.63 \pm 0.09$ & $0.63 \pm 0.09$ \\
VAT $(\mathrm{g})$ & $308 \pm 45^{*}$ & $295 \pm 47$ & & $174 \pm 71$ & $177 \pm 22$ \\
\hline
\end{tabular}

Data are provided as mean $\pm \mathrm{SD}$

$B M I$ body mass index, $F M$ fat mass, $F F M$ fat-free mass, VAT visceral adipose tissue

* Significant difference vs. females at baseline $P<0.05$

${ }^{\ddagger}$ Significant interaction effect $P<0.05$ visceral fat $(P<0.001)$ and a higher trunk to leg fat mass ratio $(P<0.001)$, whereas trunk fat mass was not different between sexes $(P=0.101$; Tables 2 and 3$)$. Following the HFHC diet, there was a trend towards an increase in total fat mass $(P=0.056)$ which was similar for males $(+1.8 \%)$ and females $(+2.3 \%$; Table 3$)$. Following the HFHC diet, there was a significant increase in trunk to leg fat mass ratio in males only $(+5.1 \%$; HFHC diet $\mathrm{x}$ sex interaction, $P=0.039$, Table 3). After the HFHC, there were no alterations in FFM, body fat percentage, visceral fat or trunk fat mass in either sex.

\section{OGTT}

At baseline, fasting plasma glucose concentrations were similar between males $\left(4.3 \pm 0.6 \mathrm{mmol} . \mathrm{L}^{-1}\right)$ and females $\left(4.2 \pm 0.4 \mathrm{mmol} . \mathrm{L}^{-1} \mathrm{~L} ; P=0.766\right)$ and after the HFHC diet, fasting glucose did not change in either sex. There were no differences in fasting serum insulin concentrations between males $\left(7.1 \pm 3.9 \mu \mathrm{lU} . \mathrm{mL}^{-1}\right)$ and females $(7.5 \pm 4.0 \mu \mathrm{lU}$. $\left.\mathrm{mL}^{-1} ; P>0.05\right)$ and this did not change following the HFHC diet in either sex. Plasma glucose AUC and insulin AUC during the OGTT were not significantly different between sexes $(P>0.05)$ and not altered following the HFHC diet in either sex $(P>0.05$; Fig. 2$)$.

\section{Insulin sensitivity}

In an attempt to decipher changes in insulin sensitivity dependent on origin (liver or muscle), glucose and insulin values from the OGTT were also used to predict hepatic and muscle insulin resistance using the calculations proposed by Abdul-Ghani et al. [41], in addition to the Matsuda ISI (46), which is a measure of whole-body insulin sensitivity. At baseline, there were no significant differences between sexes for the Matsuda ISI $(P=0.844)$, hepatic insulin resistance $(P=0.211)$ or muscle insulin resistance $(P=0.584$; Fig. 3$)$. After the HFHC diet, there were no significant changes in any of the aforementioned measures of insulin sensitivity in males nor females (Fig. 3).

\section{Metabolic flexibility}

At baseline, there were no significant differences in fasting RER between males $(0.81 \pm 0.07)$ and females $(0.76 \pm 0.08$; $P=0.189)$. Following the HFHC diet, there was a trend towards a reduction in fasting RER, which was reduced similarly between males and females post-HFHC diet $(0.78 \pm 0.08$ and $0.74 \pm 0.07$ for males and females, respectively; $P=0.052)$. At baseline, peak RER during OGTT was similar between males $(0.94 \pm 0.07)$ and females $(0.91 \pm 0.16 ; P=0.629)$. Following the HFHC diet, there was a trend towards a reduction in peak RER for males $(0.91 \pm 0.07)$ and females $(0.86 \pm 0.08 ; P=0.070)$. The time it took to reach peak RER during the OGTT was similar between males $(88 \pm 6 \mathrm{~min})$ and females $(90 \pm 7 \mathrm{~min}$; $P=0.644)$ and this did not change after the HFHC diet.

Metabolic flexibility was determined as the rate of change from fasting RER to peak RER during the OGTT. At baseline, there was no significant difference between males and females for metabolic flexibility $(P=0.877)$ and this was unaltered following the HFHC diet in both sexes $(P>0.05$; Fig. 4a).

\section{Arterial stiffness}

$\mathrm{AI}_{\mathrm{x}} @ 75$ bpm was not significantly different at baseline between sexes $(P=0.162)$ and was unaltered following the 
Fig. 2 Effect of 7-days HFHC diet on glucose and insulin values during an OGTT in males and females. No sex differences or effects of the HFHC diet on serum glucose levels (a) or plasma insulin values (b) during the OGTT. The AUC during the OGTT shows no sex differences or effects of the HFHC diet for serum glucose (c) or plasma insulin (d). For AUC graphs (c and d) solid black line represents mean value whereas dashed lines show individual responses a
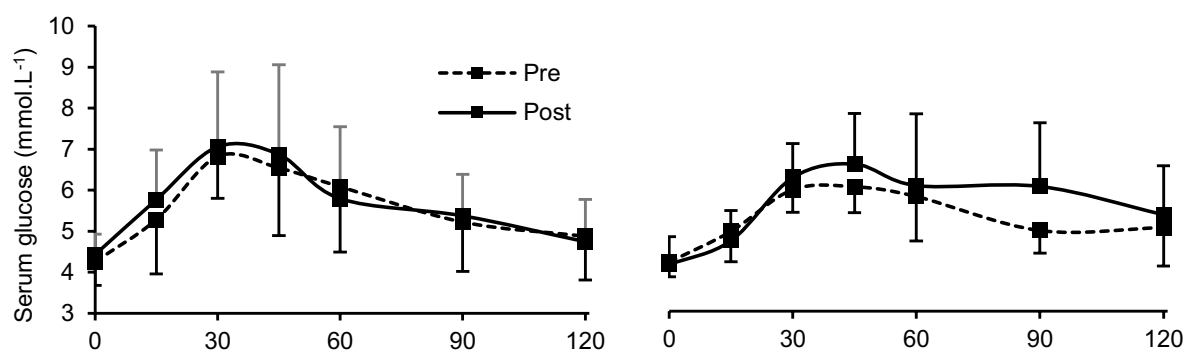

b
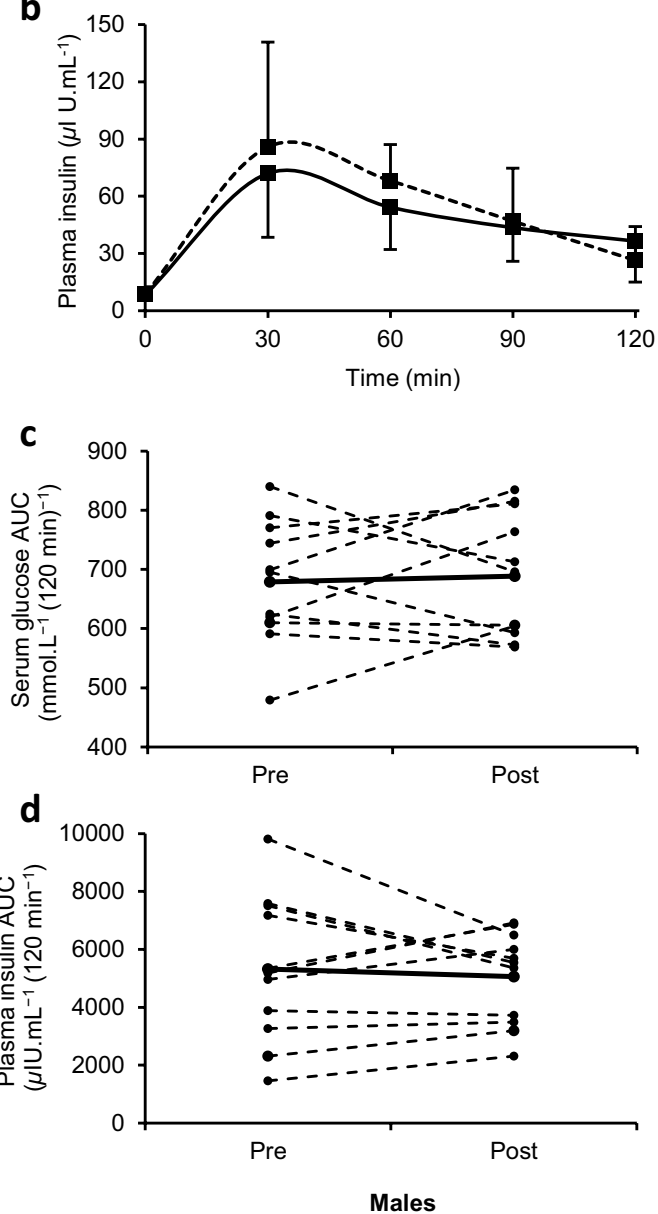
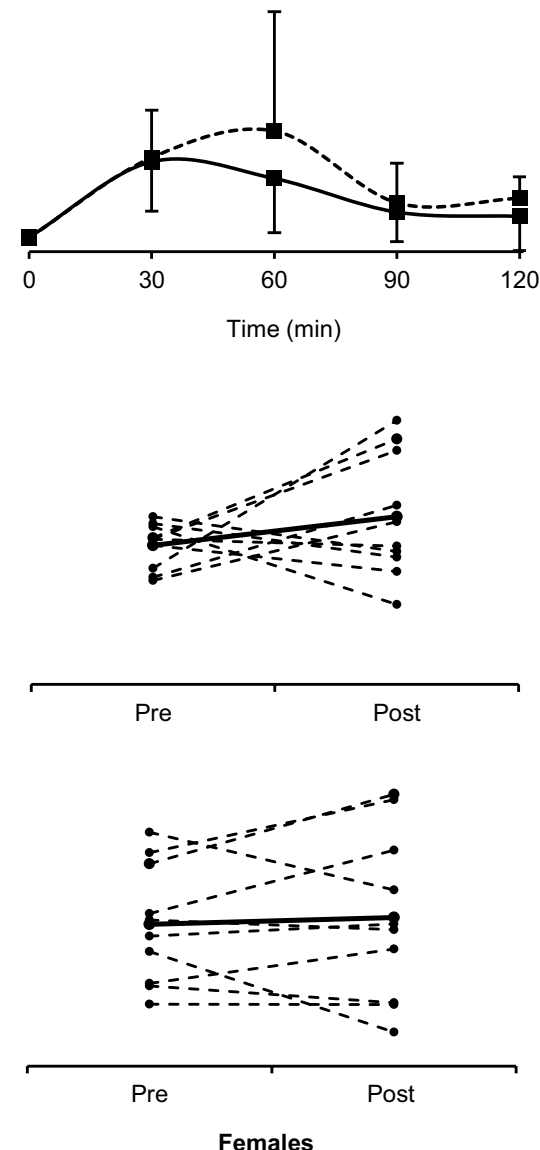

HFHC diet ( $P=0.318$; Fig. 3b). aPWV was also not significantly different at baseline between sexes $(P=0.826)$ and was unaltered after the HFHC $\operatorname{diet}(P=0.307$; Fig. 4c).

\section{Serum lipids and liver enzymes}

At baseline, there were no significant differences between sexes for serum NEFA $(P=0.912)$, cholesterol $(P=0.878)$ and triglycerides $(P=0.315$; Table 4$)$. After the HFHC diet, there was a significant increase in cholesterol $(P=0.049)$ which was similar between males $(+8.1 \%)$ and females (+6.3\%; Table 4). Triglyceride and NEFA concentrations remained unchanged following the HFHC diet for both sexes $(P=0.685$; Table 4).

Circulating liver enzymes AST, ALT and GGT were used as markers of liver damage. At baseline, there was no significant difference in AST concentration between sexes $(P=0.152)$; however, males had significantly higher ALT concentrations $(P=0.006)$ which resulted in lower AST/ALT ratio compared to females $(P=0.009)$. There was also a trend towards higher GGT concentrations in males compared to females ( $P=0.059$; Table 4$)$. After the HFHC diet, there were no significant changes in levels of AST, ALT, AST/ALT ratio or GGT in either sex $(P>0.05$; Table 4$)$. 
Fig. 3 Effect of 7-days HFHC diet on indices of insulin sensitivity measured with OGTT. No sex differences or effects of HFHC diet were seen on the Matsuda index (a), hepatic insulin resistance index (b) and muscle insulin resistance index (c) in males and females. Solid black line represents mean value whereas dashed lines show individual responses. Matsuda index was derived from Matsuda and DeFronzo [40] whilst hepatic and muscle insulin resistance indexes were derived from Abdul-Ghani et al. [41]
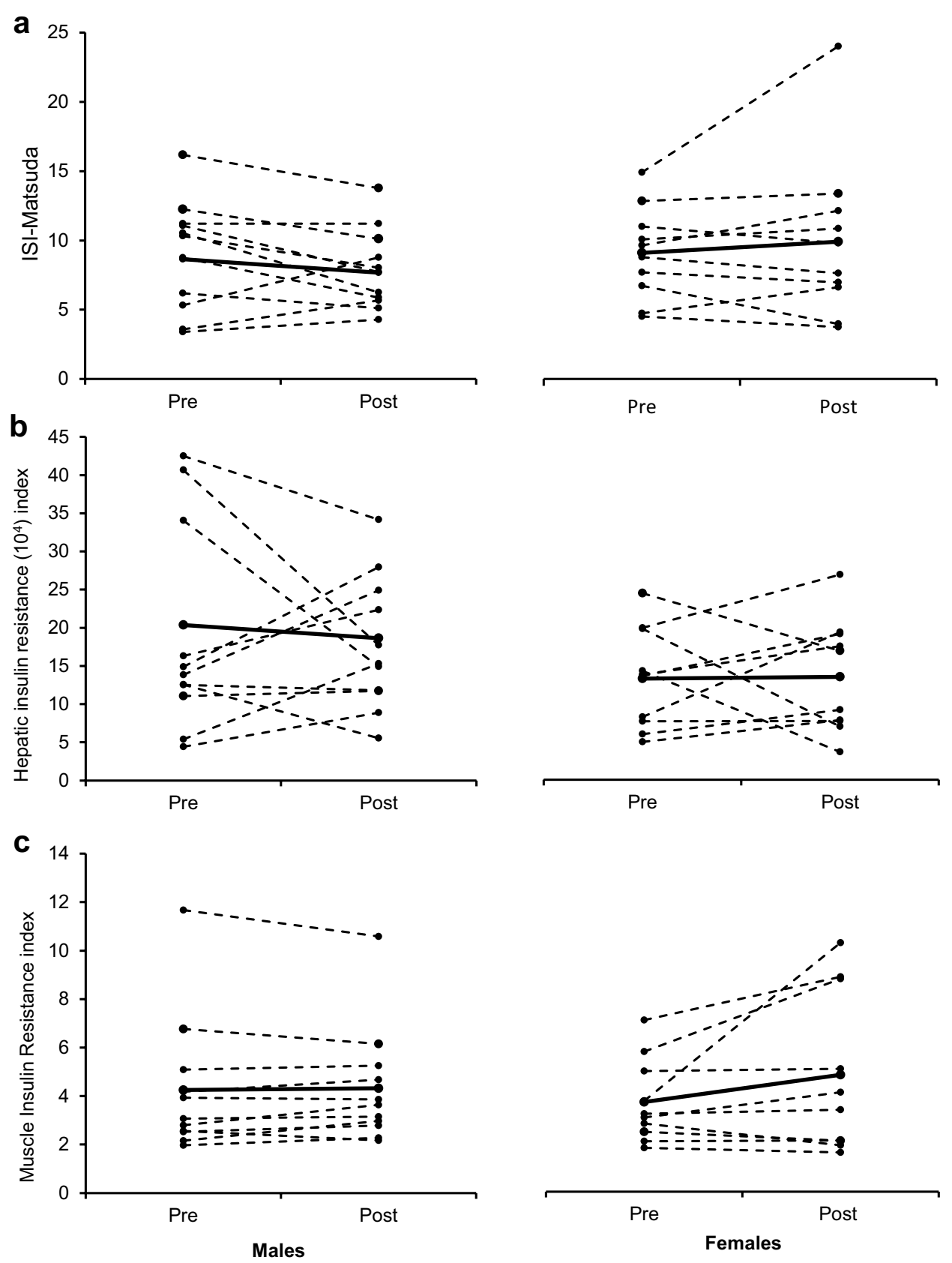

\section{Discussion}

This is the first study in humans to investigate sex differences in measurements of metabolic and cardiovascular health indicators in response to a 7-day HFHC diet. The results show there was no effect of the HFHC diet on metabolic and cardiovascular outcome measures in either sex. This highlights that young, physically active humans of both sexes who have good levels of cardio-respiratory fitness can tolerate a 7-day HFHC diet without measurable impairments in metabolic or cardiovascular health.
Of the metabolic and cardiovascular functional outcomes measured, the only variables that changed in both sexes were body fat and total cholesterol. We are the first to study and quantify changes in fat mass following a short-term (5-7 day) HFHC diet and determine sex-specific changes in a well-matched cohort. The results suggested a trend towards an increase in body fat following the HFHC diet which occurred in both sexes. In comparison to total adiposity, abdominal adiposity and in particular elevated visceral fat, are more closely associated with insulin resistance and T2D [22, 44]. In line with previous findings [45-47], at 
Fig. 4 Effect of 7-days HFHC diet on metabolic and cardiovascular functional outcomes. No sex differences or effects of HFHC diet were observed on metabolic flexibility (Peak RQ-Fasting RQ)/dt) (a), arterial stiffness (aPWV) (b) and augmentation index (@75 bpm) (c) in males and females. Solid black line represents mean value whereas dashed lines show individual responses

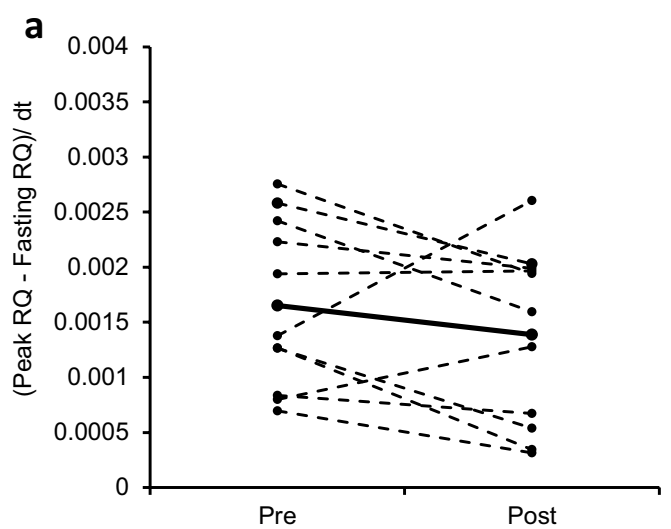

b

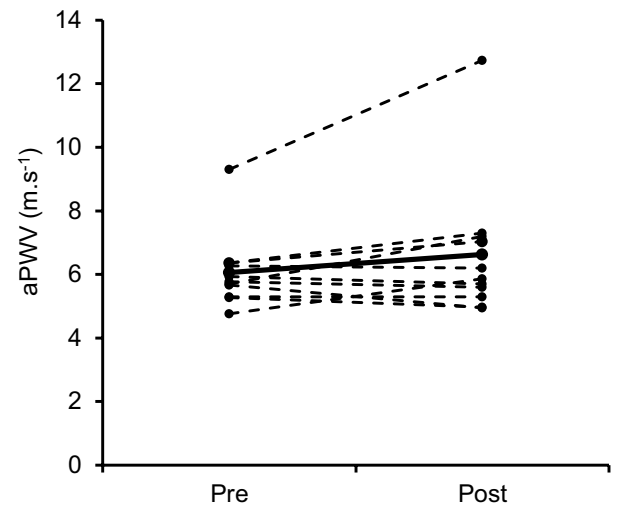

C

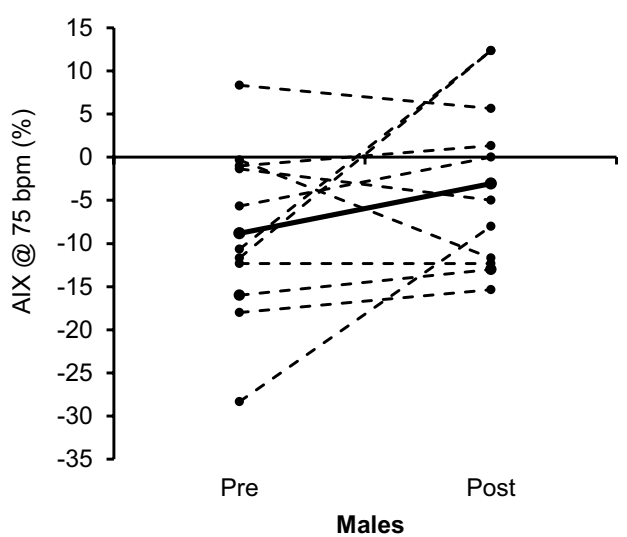

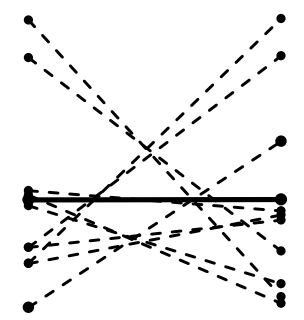

Pre

Post
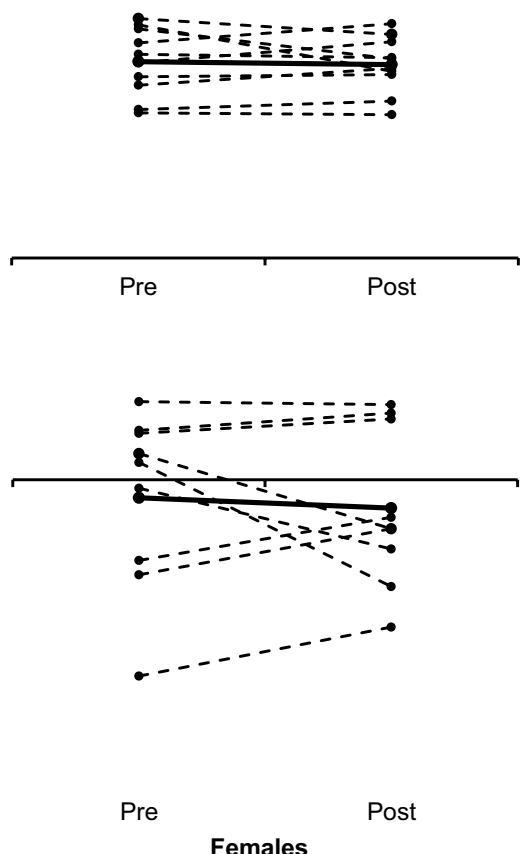

baseline visceral fat stores were higher in males compared to females, but this did not change following the HFHC diet. Trunk fat measured by the DEXA scan represents overall abdominal adiposity rather than specific visceral fat. There were no differences between males and females at baseline for trunk fat and following the HFHC diet trunk fat was not changed, but there was an increase in trunk to leg fat mass ratio which increased only in males (Table 3 ). This change in unfavourable fat accumulation ratio occurred after only 7 days of a HFHC diet but without any decrements in insulin sensitivity. It is likely that more chronic positive energy balance would exacerbate this fat accumulation in males and start to contribute to the development of metabolic disorders.
There was a trend towards a decrease in fasting RER following the HFHC diet with the difference between the sexes not being apparent. There was a large variability between participants and given the large reduction observed in RER, significance would have likely been observed if a larger cohort had been studied. Obese insulin-resistant individuals have previously been shown to exhibit lower metabolic flexibility in comparison to lean insulin-sensitive individuals [13]. In our study, metabolic flexibility was measured as the rate of change from fasting RER to peak RER during the OGTT. As there were no measurable changes from baseline following the 7-day HFHC diet in either sex, this indicates that both the females and the males were able to maintain metabolic flexibility. The current study is the only work to 
Table 4 Effect of 7-days HFHC diet on serum lipids and liver enzymes

\begin{tabular}{|c|c|c|c|c|}
\hline & \multicolumn{2}{|l|}{ Males } & \multicolumn{2}{|l|}{ Females } \\
\hline & $\operatorname{Pre}(n=11)$ & Post $(n=11)$ & Pre $(n=10)$ & Post $(n=10)$ \\
\hline \multicolumn{5}{|l|}{ Serum Lipid concentrations } \\
\hline NEFA $\left(m m o l . L^{-1}\right)$ & $1.16 \pm 0.43$ & $1.05 \pm 0.25$ & $1.17 \pm 0.26$ & $1.37 \pm 0.46$ \\
\hline Cholesterol (mmol.L $\left.\mathrm{L}^{-1}\right)$ & $3.56 \pm 0.86$ & $3.85 \pm 0.63^{\dagger}$ & $3.95 \pm 0.59$ & $4.20 \pm 0.58 \dagger$ \\
\hline Triglycerides $\left(\mathrm{mmol} . \mathrm{L}^{-1}\right)$ & $0.81 \pm 0.92$ & $0.70 \pm 0.45$ & $0.51 \pm 0.17$ & $0.59 \pm 0.25$ \\
\hline \multicolumn{5}{|l|}{ Liver enzymes } \\
\hline AST (U.L $\left.{ }^{-1}\right)$ & $35.82 \pm 7.86$ & $34.64 \pm 13.66$ & $28.10 \pm 4.52$ & $28.25 \pm 17.77$ \\
\hline $\operatorname{ALT}\left(\mathrm{U} \mathrm{L}^{-1}\right)$ & $35.36 \pm 19.80^{*}$ & $35.05 \pm 16.77$ & $16.15 \pm 7.35$ & $16.80 \pm 7.30$ \\
\hline AST/ALT ratio & $1.17 \pm 0.43^{*}$ & $1.08 \pm 0.39$ & $1.75 \pm 0.47$ & $1.62 \pm 0.36$ \\
\hline GGT $\left(\mathrm{U}^{-L^{-1}}\right)$ & $21.65 \pm 11.87$ & $21.13 \pm 8.41$ & $15.28 \pm 12.15$ & $11.56 \pm 5.39$ \\
\hline
\end{tabular}

Data are provided as mean $\pm \mathrm{SD}$

$A L T$ alanine aminotransferase, $A S T$ aspartate aminotransferase, GGT Gamma-glutamyltransferase

*Significant difference vs. females at baseline $P<0.05$

${ }^{\dagger}$ Significant main effect for the HFHC $\operatorname{diet} P<0.05$ investigate and show no sex differences in metabolic flexibility following a HFHC diet in young healthy active individuals. Whilst metabolic inflexibility is a characteristic of insulin-resistant states, our data suggest metabolic flexibility is unlikely to be compromised following an acute insult of high-fat caloric excess in individuals with high cardio-respiratory fitness.

Overall, 7 days of HFHC diet did not induce changes in whole-body insulin sensitivity (Matsuda ISI), or indices of hepatic or muscle insulin resistance. This was somewhat surprising considering previous studies have reported a reduction in measurements of insulin sensitivity following the same 7-day HFHC diet in young, healthy lean individuals $[35,36,48,49]$. The current study was novel, however, in measuring and characterising high cardio-respiratory fitness and high physical activity levels of the participants. Longitudinal studies have shown that high cardio-respiratory fitness can reduce the risk of T2D [50] and all-cause mortality [51]. Furthermore, it has been shown that high cardiorespiratory fitness reduces the risk of all-cause mortality in males who have a high BMI in comparison to males who have a normal BMI but have low cardio-respiratory fitness [52]. Low cardio-respiratory fitness is, therefore, established as an independent risk factor for all-cause mortality and may be a stronger risk factor than increased adiposity. We propose the high cardio-respiratory fitness the current cohort possessed may have protected them from the negative effects imposed from the 7-day HFHC diet in this study. To investigate this, future research should compare the metabolic and cardiovascular responses to a HFHC diet in young healthy lean participants with either low or high cardio-respiratory fitness. This study was also unique in considering the physiological variable of sex on the effects a HFHC diet by matching male and female cohorts for age, BMI and cardiorespiratory fitness. We show for the first time there were no sex differences in their response to a HFHC diet when young, healthy participants are investigated.

This was the first study to measure arterial stiffness response to a HFHC diet. Here, it was demonstrated that similar to insulin sensitivity, a 7-day HFHC diet does not appear to be of sufficient duration to impair this cardiovascular functional outcome measure in either sex of young healthy participants. There were also no increases in the circulating concentrations of liver enzymes, AST, ALT and GGT which are early biomarkers of lipid accumulation in the liver [53]. It should be noted that males had a higher ALT concentration resulting in a lower AST/ALT ratio at baseline and after the HFHC diet. Elevated ALT is associated with fatty liver and non-alcoholic fatty liver disease but does not define a specific disease [54]. The reported upper limit of normal of ALT varies greatly between laboratories and sexes (35-79 U.L ${ }^{-1}$ for males and 31-55 U.L ${ }^{-1}$ for females) [55], and although it is established that healthy males have higher ALT concentrations compared to healthy females [56], the mechanisms underpinning this differences are unknown [57]. The two-fold greater ALT concentration in males compared to females in the present study reflects the available epidemiological data [54-57] but is not elevated to an extent which might suggest signs of NAFLD. We anticipated to see increases in the plasma concentration of both triacylglycerol and fatty acids as markers of lipid overload; however, none of these plasma lipid concentrations increased following the HFHC diet in either sex (Table 4). We did, however, observe a significant increase in the plasma total cholesterol concentration in both sexes following the 7-day HFHC diet (Table 4), contradicting previous findings showing no change in total cholesterol following 5-day HFHC diet in males only [33]. Unfortunately, we 
were unable to interrogate this further to understand whether these increases were due to changes in HDL and/or LDL cholesterol.

Obesity is often associated with reduced PA levels and consumption of HFHC diets. A recent systematic review concluded that HFHC diet studies can often influence participant's PA levels, which may impact changes in weight gain [58]. In the current study, all participants exhibited high habitual PA levels with the IPAQ and this was largely due to participants participating in regular structured exercise. Participants continued their regular exercise regime throughout the 7-day HFHC diet period and habitual daily energy expenditure measured with accelerometry was the same before and during the diet period. This, in addition to good levels of cardio-respiratory fitness could explain why both male and female participants in our study were able to compensate for the potential negative effects of the 7-day HFHC diet. Another study showed that the combination of both reduced PA and HFHC diet led to larger (significant) reductions in insulin sensitivity in healthy young males [59]. A limitation of the present study is that only young participants with good levels of cardio-respiratory fitness were recruited. Further work is now required to determine whether good levels of cardio-respiratory fitness in both young and older adults compensates the effects of a HFHC.

In summary, this study observed no main effects of a 7-day HFHC diet on metabolic and cardiovascular functional outcomes in lean young healthy individuals of either sex with high levels of cardio-respiratory fitness. More research needs to be conducted to examine if the high cardio-respiratory levels protected both sexes from the expected negative effects of the HFHC diet. Despite participants maintaining high levels of PA, the male cohort did experience an increase in trunk to leg fat mass ratio following the HFHC diet, which may be exacerbated with reduced PA. Although epidemiological studies have shown that there is a reduced prevalence of insulin resistance and T2D in females, the underlying mechanisms of this sex difference are currently understudied and not understood. We conclude that future research should investigate whether a repeat of the current study in males and females with a lower cardio-respiratory fitness will exacerbate the negative metabolic and cardiovascular functional outcomes and thus reveal the mechanisms leading to a higher T2D risk in males than in females.

Funding This study was supported by a grant from the Society for Endocrinology and Liverpool John Moores University PhD scholarship.

\section{Compliance with ethical standards}

Conflict of interest There are no conflicts of interest.

Open Access This article is licensed under a Creative Commons Attribution 4.0 International License, which permits use, sharing, adaptation, distribution and reproduction in any medium or format, as long as you give appropriate credit to the original author(s) and the source, provide a link to the Creative Commons licence, and indicate if changes were made. The images or other third party material in this article are included in the article's Creative Commons licence, unless indicated otherwise in a credit line to the material. If material is not included in the article's Creative Commons licence and your intended use is not permitted by statutory regulation or exceeds the permitted use, you will need to obtain permission directly from the copyright holder. To view a copy of this licence, visit http://creativecommons .org/licenses/by/4.0/.

\section{References}

1. Kearney $\mathbf{J}$ (2010) Food consumption trends and drivers. Philos Trans R Soc Lond B Biol Sci 365(1554):2793-2807. https://doi. org/10.1098/rstb.2010.0149

2. Townsend N, Bhatnagar P, Wickramasinghe K, Scarborough P, Foster C, Rayner M (2012) Physical activity statistics 2012. British Heart Foundation, London

3. British Heart Foundation (2017) Physical inactivity Report 2017. https://www.bhf.org.uk/informationsupport/publicatio ns/statistics/physical-inactivity-report-2017

4. Katzmarzyk PT (2010) Physical activity, sedentary behavior, and health: paradigm paralysis or paradigm shift? Diabetes 59(11):2717-2725. https://doi.org/10.2337/db10-0822

5. Naja F, Hwalla N, Itani L, Karam S, Sibai AM, Nasreddine L (2015) A Western dietary pattern is associated with overweight and obesity in a national sample of Lebanese adolescents (1319 years): a cross-sectional study. Br J Nutr 114(11):1909-1919. https://doi.org/10.1017/S0007114515003657

6. Tuomilehto J, Lindstrom J, Eriksson JG, Valle TT, Hamalainen $\mathrm{H}$, Ilanne-Parikka P, Keinanen-Kiukaanniemi S, Laakso M, Louheranta A, Rastas M, Salminen V, Uusitupa M, Finnish Diabetes Prevention Study G (2001) Prevention of type 2 diabetes mellitus by changes in lifestyle among subjects with impaired glucose tolerance. N Engl J Med 344(18):1343-1350. https:// doi.org/10.1056/NEJM200105033441801

7. Groban L, Lindsey SH, Wang H, Alencar AK (2016) Chapter 5-Sex and Gender Differences in Cardiovascular Disease. In: Neigh GN, Mitzelfelt MM (eds) Sex Differences in Physiology. Academic Press, Boston, pp 61-87. https://doi. org/10.1016/B978-0-12-802388-4.00005-7

8. Laakso M (2010) Cardiovascular disease in type 2 diabetes from population to man to mechanisms: the Kelly West Award Lecture 2008. Diabetes Care 33(2):442-449. https://doi. org/10.2337/dc09-0749

9. DeFronzo RA (2004) Pathogenesis of type 2 diabetes mellitus. Med Clin North Am 88(4):787-835. https://doi.org/10.1016/j. mcna.2004.04.013

10. Perry RJ, Samuel VT, Petersen KF, Shulman GI (2014) The role of hepatic lipids in hepatic insulin resistance and type 2 diabetes. Nature 510(7503):84-91. https://doi.org/10.1038/natur e13478

11. Galgani JE, Heilbronn LK, Azuma K, Kelley DE, Albu JB, PiSunyer X, Smith SR, Ravussin E, Look AARG (2008) Metabolic flexibility in response to glucose is not impaired in people with type 2 diabetes after controlling for glucose disposal rate. Diabetes 57(4):841-845. https://doi.org/10.2337/db08-0043

12. Kelley DE, Mandarino LJ (2000) Fuel selection in human skeletal muscle in insulin resistance: a reexamination. Diabetes 49(5):677-683 
13. Kelley DE, Goodpaster B, Wing RR, Simoneau JA (1999) Skeletal muscle fatty acid metabolism in association with insulin resistance, obesity, and weight loss. Am J Physiol 277(6 Pt 1):E1130-1141

14. Abdullah A, Peeters A, de Courten M, Stoelwinder J (2010) The magnitude of association between overweight and obesity and the risk of diabetes: a meta-analysis of prospective cohort studies. Diabetes Res Clin Pract 89(3):309-319. https://doi.org/10.1016/j. diabres.2010.04.012

15. Bastien M, Poirier P, Lemieux I, Despres JP (2014) Overview of epidemiology and contribution of obesity to cardiovascular disease. Prog Cardiovasc Dis 56(4):369-381. https://doi. org/10.1016/j.pcad.2013.10.016

16. Berg AH, Scherer PE (2005) Adipose tissue, inflammation, and cardiovascular disease. Circ Res 96(9):939-949. https://doi. org/10.1161/01.RES.0000163635.62927.34

17. Despres JP (2006) Intra-abdominal obesity: an untreated risk factor for type 2 diabetes and cardiovascular disease. J Endocrinol Invest 29(3 Suppl):77-82

18. Huang HD, Yang CM, Shu HF, Kuang YQ, Yang T, He WQ, Zhao K, Xia X, Cheng JM, Ma Y, Gu JW (2015) Genetic predisposition of stroke: understanding the evolving landscape through metaanalysis. Int J Clin Exp Med 8(1):1315-1323

19. Racette SB, Evans EM, Weiss EP, Hagberg JM, Holloszy JO (2006) Abdominal adiposity is a stronger predictor of insulin resistance than fitness among 50-95 year olds. Diabetes Care 29(3):673-678. https://doi.org/10.2337/diacare.29.03.06. dc05-1605

20. Park SY, Kwon KY, Kim JH, Choi HH, Han KH, Han JH (2014) Association between appendicular fat mass and metabolic risk factors. Korean J Fam Med 35(4):182-189. https://doi.org/10.4082/ kjfm.2014.35.4.182

21. Janjic D (1996) Android-type obesity and gynecoid-type obesity. Praxis (Bern 1994) 85(49):1578-1583

22. Montague CT, O'Rahilly S (2000) The perils of portliness: causes and consequences of visceral adiposity. Diabetes 49(6):883-888

23. Wild S, Roglic G, Green A, Sicree R, King H (2004) Global prevalence of diabetes: estimates for the year 2000 and projections for 2030. Diabetes Care 27(5):1047-1053

24. Kuhl J, Hilding A, Ostenson CG, Grill V, Efendic S, Bavenholm P (2005) Characterisation of subjects with early abnormalities of glucose tolerance in the Stockholm Diabetes Prevention Programme: the impact of sex and type 2 diabetes heredity. Diabetologia 48(1):35-40. https://doi.org/10.1007/s00125-004-1614-1

25. Munguia-Miranda C, Sanchez-Barrera RG, Tuz K, Alonso-Garcia AL, Cruz M (2009) Impaired fasting glucose detection in blood donors population. Rev Med Inst Mex Seguro Soc 47(1):17-24

26. Clausen JO, Borch-Johnsen K, Ibsen H, Bergman RN, Hougaard P, Winther K, Pedersen O (1996) Insulin sensitivity index, acute insulin response, and glucose effectiveness in a population-based sample of 380 young healthy Caucasians. Analysis of the impact of gender, body fat, physical fitness, and life-style factors. J Clin Invest 98(5):1195-1209. https://doi.org/10.1172/JCI118903

27. Borissova AM, Tankova T, Kirilov G, Koev D (2005) Gender-dependent effect of ageing on peripheral insulin action. Int J Clin Pract 59(4):422-426. https://doi.org/10.111 1/j.1368-5031.2005.00209.x

28. Donahue RP, Prineas RJ, DeCarlo DR, Bean JA, Skyler JS (1996) The female 'insulin advantage' in a biracial cohort: results from the Miami Community Health Study. Int J Obes Relat Metab Disord 20(1):76-82

29. Nuutila P, Knuuti MJ, Maki M, Laine H, Ruotsalainen U, Teras M, Haaparanta M, Solin O, Yki-Jarvinen H (1995) Gender and insulin sensitivity in the heart and in skeletal muscles. Studies using positron emission tomography. Diabetes 44(1):31-36
30. Rattarasarn C, Leelawattana R, Soonthornpun S, Setasuban W, Thamprasit A (2004) Gender differences of regional abdominal fat distribution and their relationships with insulin sensitivity in healthy and glucose-intolerant Thais. J Clin Endocrinol Metab 89(12):6266-6270. https://doi.org/10.1210/jc.2004-0209

31. Yki-Jarvinen H (1984) Sex and insulin sensitivity. Metabolism 33(11):1011-1015

32. Hoeg LD, Sjoberg KA, Jeppesen J, Jensen TE, Frosig C, Birk JB, Bisiani B, Hiscock N, Pilegaard H, Wojtaszewski JF, Richter EA, Kiens B (2011) Lipid-induced insulin resistance affects women less than men and is not accompanied by inflammation or impaired proximal insulin signaling. Diabetes 60(1):64-73. https ://doi.org/10.2337/db10-0698

33. Brons C, Jensen CB, Storgaard H, Hiscock NJ, White A, Appel JS, Jacobsen S, Nilsson E, Larsen CM, Astrup A, Quistorff B, Vaag A (2009) Impact of short-term high-fat feeding on glucose and insulin metabolism in young healthy men. J Physiol 587(Pt 10):2387-2397. https://doi.org/10.1113/jphysiol.2009.169078

34. Bakker LE, van Schinkel LD, Guigas B, Streefland TC, Jonker JT, van Klinken JB, van der Zon GC, Lamb HJ, Smit JW, Pij1 H, Meinders AE, Jazet IM (2014) A 5-day high-fat, high-calorie diet impairs insulin sensitivity in healthy, young South Asian men but not in Caucasian men. Diabetes 63(1):248-258. https://doi. org/10.2337/db13-0696

35. Hulston CJ, Churnside AA, Venables MC (2015) Probiotic supplementation prevents high-fat, overfeeding-induced insulin resistance in human subjects. Br J Nutr 113(4):596-602. https://doi. org/10.1017/S0007114514004097

36. Parry SA, Smith JR, Corbett TRB, Woods RM, Hulston CJ (2017) Short-term, high-fat overfeeding impairs glycaemic control but does not alter gut hormone responses to a mixed meal tolerance test in healthy, normal-weight individuals. Br J Nutr 117(1):4855. https://doi.org/10.1017/S0007114516004475

37. Compher C, Frankenfield D, Keim N, Roth-Yousey L, Evidence Analysis Working G (2006) Best practice methods to apply to measurement of resting metabolic rate in adults: a systematic review. J Am Diet Assoc 106(6):881-903. https://doi. org/10.1016/j.jada.2006.02.009

38. Weir JB (1949) New methods for calculating metabolic rate with special reference to protein metabolism. J Physiol 109(1-2):1-9

39. Cocks M, Shaw CS, Shepherd SO, Fisher JP, Ranasinghe AM, Barker TA, Tipton KD, Wagenmakers AJ (2013) Sprint interval and endurance training are equally effective in increasing muscle microvascular density and eNOS content in sedentary males. J Physiol 591(3):641-656. https://doi.org/10.1113/jphys iol.2012.239566

40. Matsuda M, DeFronzo RA (1999) Insulin sensitivity indices obtained from oral glucose tolerance testing: comparison with the euglycemic insulin clamp. Diabetes Care 22(9):1462-1470

41. Abdul-Ghani MA, Matsuda M, Balas B, DeFronzo RA (2007) Muscle and liver insulin resistance indexes derived from the oral glucose tolerance test. Diabetes Care 30(1):89-94. https://doi. org/10.2337/dc06-1519

42. Cook A, Pryer J, Shetty P (2000) The problem of accuracy in dietary surveys. Analysis of the over 65 UK National Diet and Nutrition Survey. J Epidemiol Community Health 54(8):611-616. https://doi.org/10.1136/jech.54.8.611

43. Craig CL, Marshall AL, Sjostrom M, Bauman AE, Booth ML, Ainsworth BE, Pratt M, Ekelund U, Yngve A, Sallis JF, Oja P (2003) International physical activity questionnaire: 12-country reliability and validity. Med Sci Sports Exerc 35(8):1381-1395. https://doi.org/10.1249/01.MSS.0000078924.61453.FB

44. Huang T, Qi Q, Zheng Y, Ley SH, Manson JE, Hu FB, Qi L (2015) Genetic predisposition to central obesity and risk of type 2 diabetes: two independent cohort studies. Diabetes Care 38(7):13061311. https://doi.org/10.2337/dc14-3084 
45. Haupt A, Thamer C, Heni M, Machicao F, Machann J, Schick F, Stefan N, Fritsche A, Haring HU, Staiger H (2010) Novel obesity risk loci do not determine distribution of body fat depots: a wholebody MRI/MRS study. Obesity (Silver Spring) 18(6):1212-1217. https://doi.org/10.1038/oby.2009.413

46. Ludescher B, Najib A, Baar S, Machann J, Thamer C, Schick F, Buchkremer G, Claussen CD, Eschweiler GW (2007) Gender specific correlations of adrenal gland size and body fat distribution: a whole body MRI study. Horm Metab Res 39(7):515-518. https://doi.org/10.1055/s-2007-982518

47. Staiano AE, Katzmarzyk PT (2012) Ethnic and sex differences in body fat and visceral and subcutaneous adiposity in children and adolescents. Int J Obes (Lond) 36(10):1261-1269. https://doi. org/10.1038/ijo.2012.95

48. Parry SA, Turner MC, Woods RM, James LJ, Ferguson RA, Cocks M, Whytock KL, Strauss JA, Shepherd SO, Wagenmakers AJM, van Hall G, Hulston CJ (2020) High-fat overfeeding impairs peripheral glucose metabolism and muscle microvascular eNOS Ser1177 phosphorylation. J Clin Endocrinol Metab 105(1):dgz018. https://doi.org/10.1210/clinem/dgz018

49. Whytock KL, Parry SA, Turner MC, Woods RM, James LJ, Ferguson RA, Stahlman M, Boren J, Strauss JA, Cocks M, Wagenmakers AJM, Hulston CJ, Shepherd SO (2020) A 7-day high-fat, high-calorie diet induces fibre-specific increases in intramuscular triglyceride and perilipin protein expression in human skeletal muscle. J Physiol 598(6):1151-1167. https://doi.org/10.1113/ JP279129

50. Nojima H, Yoneda M, Watanabe H, Yamane K, Kitahara Y, Sekikawa K, Yamamoto H, Yokoyama A, Hattori N, Kohno N, Stud HUHP (2017) Association between aerobic capacity and the improvement in glycemic control after the exercise training in type 2 diabetes. Diabetol Metab Syndr 9:1-10. https://doi.org/10.1186/ s13098-017-0262-9

51. Blair SN, Kohl HW 3rd, Paffenbarger RS Jr, Clark DG, Cooper KH, Gibbons LW (1989) Physical fitness and all-cause mortality. A prospective study of healthy men and women. JAMA 262(17):2395-2401
52. Lee CD, Jackson AS, Blair SN (1998) US weight guidelines: is it also important to consider cardiorespiratory fitness? Int J Obes Relat Metab Disord 22(Suppl 2):S2-7

53. Sanyal D, Mukherjee P, Raychaudhuri M, Ghosh S, Mukherjee S, Chowdhury S (2015) Profile of liver enzymes in non-alcoholic fatty liver disease in patients with impaired glucose tolerance and newly detected untreated type 2 diabetes. Indian J Endocrinol Metab 19(5):597-601. https://doi.org/10.4103/2230-8210.163172

54. Sung KC, Lee MY, Lee JY, Lee SH, Kim SH, Kim SH (2019) Utility of ALT concentration in men and women with nonalcoholic fatty liver disease: cohort study. J Clin Med. https://doi. org/10.3390/jcm8040445

55. Neuschwander-Tetri BA, Unalp A, Creer MH, Nonalcoholic Steatohepatitis Clinical Research N (2008) Influence of local reference populations on upper limits of normal for serum alanine aminotransferase levels. Arch Intern Med 168(6):663-666. https ://doi.org/10.1001/archinternmed.2007.131

56. Prati D, Taioli E, Zanella A, Della Torre E, Butelli S, Del Vecchio E, Vianello L, Zanuso F, Mozzi F, Milani S, Conte D, Colombo M, Sirchia G (2002) Updated definitions of healthy ranges for serum alanine aminotransferase levels. Ann Intern Med 137(1):110. https://doi.org/10.7326/0003-4819-137-1-200207020-00006

57. Wu L, He Y, Jiang B, Liu M, Yang S, Wang Y, Zeng J, Yao Y, Wang J (2017) Gender difference in the association between aminotransferase levels and hypertension in a Chinese elderly population. Medicine (Baltimore) 96(21):e6996. https://doi.org/10.1097/ MD.0000000000006996

58. Giroux V, Saidj S, Simon C, Laville M, Segrestin B, Mathieu ME (2018) Physical activity, energy expenditure and sedentary parameters in overfeeding studies - a systematic review. BMC Public Health 18(1):903. https://doi.org/10.1186/s12889-018-5801-2

59. Knudsen SH, Hansen LS, Pedersen M, Dejgaard T, Hansen J, Hall GV, Thomsen C, Solomon TP, Pedersen BK, Krogh-Madsen $\mathrm{R}$ (2012) Changes in insulin sensitivity precede changes in body composition during 14 days of step reduction combined with overfeeding in healthy young men. J Appl Physiol (1985) 113(1):7-15. https://doi.org/10.1152/japplphysiol.00189.2011 